\title{
The Antecedent and Consequence of Trust in Social Shopping
}

\author{
Haengnam Sung ${ }^{1}$, Won-Jong Kim ${ }^{2}$, Jae-Ik Shin ${ }^{3 *}$ \\ ${ }^{1}$ Dept. of Management Information System, Gyeongsang National University, \\ 501 Jinju-Daero, Jinju 52828, South Korea \\ ${ }^{2}$ Dept. of Business Administration, Gyeongsang National University, \\ 501 Jinju-Daero, Jinju 52828, South Korea \\ ${ }^{3}$ Dept. of E-Business, Gyeongnam National University of Science and Technology, \\ 33 Dongjin-Ro, Jinju 52725, South Korea \\ sji@gntech.ac.kr
}

\begin{abstract}
The continuous fever of social media shows that social shopping signifies the main future e-commerce opportunities. For academics, it would be one of the most important and stimulating research topics, which creates values of great theoretical and practical implication. This paper aims to reveal the importance of understanding trust in a website and trust in product recommendation to enhance purchase intention through social network service (perceived ability, perceived integrity, and perceived critical mass). The research model is empirically tested with survey data from 170 respondents who have experienced social shopping in South Korea. The findings indicated that social network service can be conceptualized as a composite of three dimensions (perceived ability, perceived integrity, and perceived critical mass) and perceived critical mass is the most important factor for social network service. Second, social network service has positive influences on trust in a website, trust in product recommendation, and purchase intention. Interestingly, social network service has the most effect on trust in a website and the least effect on trust in product recommendation. Third, trust in a website has positive influences on trust in product recommendation and purchase intention. Fourth, trust in product recommendation has a positive influence on purchase intention. While social network service has the most impact on purchase intention of social shopping, trust in a website has the least impact on it. Thus, the research model demonstrated the importance of social network service to purchase intention. Social shopping websites should focus on establishing the higher level of social network service that can provide the useful information about product recommendations and effective website designs that customers trust.
\end{abstract}

Keywords: Social Network Service, Trust in a Website, Trust in Product Recommendation, Purchase Intention

\section{Introduction}

Social commerce has gained popularity recently because its evolution emphasizes the role of online social networking in furthering business [1]. Consumers could find, share, commend and evaluate products, exchange shopping information, knowledge and opinions and make transactions through their personal online social network ties [2].

Shen [3] saw a social shopping website as an innovative business model based on online social networking since it could enable retailers to grasp potential customers in a new method [4]. Consumers' participation in a social shopping website is critical because their participation can augment member-generated contents, motivating more interaction

* Corresponding Author 
among the members. Moreover, the performance and quality of a social shopping website depend on consumers' participation which can leverage the positive social shopping results [5]. Thus, understanding customer behavior on social shopping websites is very important job for marketers to maximize positive retailing performances.

Social commerce constructs is defined as online forums, ratings, communities, reviews and recommendations [6]. The information provided by these social commerce platforms or communities can have an influence on potential customers' buying intention. More and more researchers have begun to study the constructs [7].

Security and trust is crucial for an online commerce environment [8]. Individual consumers tend to perform the transaction only in conditions of current trust. Hajli [6] suggested that trust is a vital factor in online social community. Some previous studies have examined trust in a website or trust in online communities [7, 9], but few studies have focused on trust in product recommendation $[10,11,12,13]$.

The antecedent variable of trust in buyers' recommendations on the social network has rarely been discussed in spite of many researches on internet. For examining the possible antecedents of trust in recommendations, Hsiao et al. [10] performed a questionnaire survey based on an open-ended question and suggested that perceived ability, perceived benevolence/integrity, and perceived critical mass of the reviewers were the three most repeatedly mentioned reasons for trusting the recommendations of purchasers. However, they did not consider the three constructs as antecedents of trust in a website. Prior studies showed that perceived vendor reputation, perceived site quality, and structural assurance of the web have been widely used as antecedents of trust in a website $[14,15]$. Besides trust in recommendations, trust in websites is another important predictor affecting online shopping behaviors [16].

Thus, it is meaningful to investigate the roles of trust in a website and trust in product recommendation in the relationship between social network service and purchase intention. This study investigates the role of social network service in order to build trust in a website and trust in product recommendation. It also examines how social network service affects purchase intention.

\section{Theoretical Background and Hypothesis}

Hajli [6] suggested that potential customers mention and recommend products or services through social network activities such as communities, ratings, reviews, referrals, and recommendations. The constructs are expected to influence successful social commerce. Meanwhile, online communities give people in the social network the opportunity to share interest and acquire knowledge [17].

Ability is the members' perception of online communities' competencies and knowledge noticeable to the expected performance [18]. In the setting of social networks, ability is also the powerful antecedent to create trust among the members who usually focus on a specific mutual interest, hobby, and event [18]. A trustee who obeys moral standards such as trustworthiness could increase a trustor's confidence in the trustee's behavior [10]. Hsiao et al. [10] proposed perceived ability and perceived integrity as two key factors of trust in product recommendations. They also suggested that because consumers are inclined to trust more in the recommendations from large numbers of other consumers, perceived critical mass can be another antecedent of trust in product recommendation. Meanwhile, Lu et al. [19] suggested that social presence of web and social presence of interaction positively influence trust in sellers.

According to social psychology research, human can learn from and be influenced by the knowledge and experiences of other people who they know or trust [20]. Trust can be established through social interactions with other members and the social network environment [19]. Because of the absence of effective regulation over the opportunistic behaviors of e-vendors in the online transactions, people are more likely to transact 
business with the vendors which they trust. In addition, people tend more to trust the information provided by other purchasers like themselves more than that provided by firms [21]. Through consumers' trust in the opinions or recommendations shared by other buyers, websites may augment their sales. Thus, trust is often deemed the base of ecommerce [22] and the most vital factor for the success of e-commerce [23].

Teo and $\mathrm{Yu}$ [24] suggested that shoppers may buy products from a website considering economic value when their purchase intention toward the products has been formed by others' recommendations. Chevalier and Mayzlin [25] proposed that other shoppers' product recommendations have an effect on their purchasing behavior at web sites. Kim et al. [26] identified that buyers' intention to buy products online was also affected by trust in the web seller. Rahimnia and Hassanzadeh [27] also suggested that e-trust positively affects e-marketing effectiveness. Trust in sellers is also identified to positively affect purchase intention of social commerce [19]. Meanwhile, social commerce uses relationships on social networking platforms as the medium for social sharing about products or sellers to persuade curiosity in a product, thereby growing the purchase intention [28].

To identify the relationships between social network service, trust in a website, trust in product recommendation, and purchase intention of social shopping, we propose the following hypotheses.

H1 Social network service positively drives trust in a website of online community.

H2 Social network service positively drives trust in product recommendation of online community.

H3 Trust in a website positively drives trust in product recommendation of online community.

H4 Social network service positively drives purchase intention of online community.

H5 Trust in a website positively drives purchase intention of online community.

H6 Trust in product recommendation positively drives purchase intention of online community.

\section{Research Methodology}

As shown in Figure 1 research model proposes a structure to explore the effects of social network service on two types of trust and purchase intention in social shopping websites.

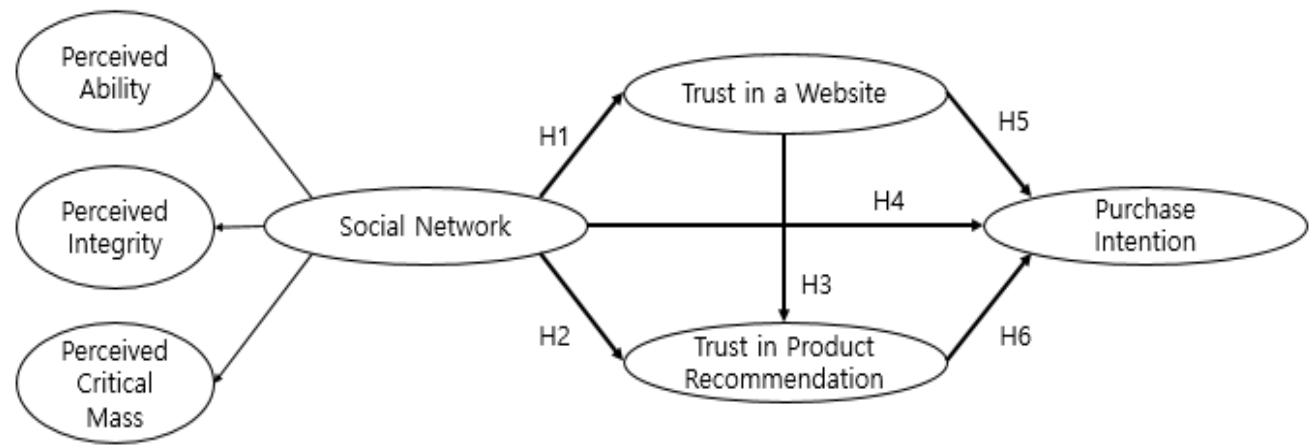

Figure 1. Research Model

The items were borrowed from previous studies in the literature of online social shopping and were modified for this research. The scale items for perceived ability, perceived integrity, and perceived critical mass of social network were adapted from Lou 
et al. [11], Ridings et al. [12], and Hsiao et al. [10]. The scale items for trust in a website and trust in product recommendation were adapted from Gefen [29], Hsiao et al. [10] and Sung et al. [13]. The scale items for purchase intention were adapted from Teo and $\mathrm{Yu}$ [24] and Hsiao et al. [10]. The items were measured on a seven-point Likert-type scale, ranging from "disagree strongly" (1) to "agree strongly" (7). Table 1 shows the modified questionnaire.

Table 1. Questionnaire Items

\begin{tabular}{|c|c|c|c|}
\hline \multicolumn{2}{|c|}{ Constructs } & Measurement Scales & Source \\
\hline \multirow{3}{*}{$\begin{array}{c}\text { Social } \\
\text { Net } \\
\text { work }\end{array}$} & $\begin{array}{c}\text { Perceived } \\
\text { Ability }\end{array}$ & $\begin{array}{l}\text { 1. The members of the online community have } \\
\text { knowledge about the issue. } \\
\text { 2. The members of the online community are capable of } \\
\text { taking part in the issue. } \\
\text { 3. The members of the online community have enough } \\
\text { qualification for the issue. }\end{array}$ & \multirow{3}{*}{$\begin{array}{l}{[10} \\
11 \\
12 \\
13]\end{array}$} \\
\hline & $\begin{array}{l}\text { Perceived } \\
\text { Integrity }\end{array}$ & $\begin{array}{l}\text { 1. The members of the online community are concerned } \\
\text { about what is important to other people } \\
2 \text {. The members of the online community will do their } \\
\text { best to assist other people. } \\
3 \text {. The members of the online community are impartial } \\
\text { to other people. } \\
4 \text {. The members of the online community are truthful } \\
\text { with other people. }\end{array}$ & \\
\hline & $\begin{array}{l}\text { Perceived } \\
\text { Critical } \\
\text { Mass }\end{array}$ & $\begin{array}{l}\text { 1. There are many members in the online community. } \\
\text { 2. The members of the online community often interact. } \\
\text { 3. The members of the online community take part in } \\
\text { product rating actively. }\end{array}$ & \\
\hline \multicolumn{2}{|c|}{ Trust in a Website } & $\begin{array}{l}\text { 1. The website is reliable. } \\
\text { 2. I trust the website. } \\
\text { 3. I think that the website is dependable. }\end{array}$ & \multirow[b]{2}{*}{$\begin{array}{l}{[10} \\
13 \\
28]\end{array}$} \\
\hline \multicolumn{2}{|c|}{$\begin{array}{l}\text { Trust in Product } \\
\text { Recommendation }\end{array}$} & $\begin{array}{l}\text { 1. The product recommendations of the online } \\
\text { community are reliable. } \\
\text { 2. I rely on the product recommendations of the online } \\
\text { community. } \\
\text { 3. The product recommendations of the online } \\
\text { community are dependable. }\end{array}$ & \\
\hline \multicolumn{2}{|c|}{ Purchase Intention } & $\begin{array}{l}\text { 1. I would consider purchasing the recommended } \\
\text { product from the online community. } \\
\text { 2. I am likely to purchase the recommended product } \\
\text { from the online community. } \\
\text { 3. I am willing to purchase the recommended product } \\
\text { from the online community. }\end{array}$ & $\begin{array}{l}{[10} \\
13 \\
23]\end{array}$ \\
\hline
\end{tabular}

\section{Data Analysis and Results}

The data for this research were collected from 200 respondents who understand online social shopping. A questionnaire survey was performed from October 26 to November 6 , 2015. After eliminating the incomplete responses, 170 questionnaires were employed in the data analysis. Of those, 74.7 percent of respondents were female, and most respondents were in their 20s and 30s. 77.1 percent had experienced online communities and 53.5 percent had purchase experiences through online communities, indicating that the data mostly represented the assessments of online social shopping. Table 2 presents the demographic profile. 
Table 2. Demographic Profile

\begin{tabular}{|c|c|c|c|}
\hline \multicolumn{2}{|c|}{ Measure (Items) } & Frequency & Percent (\%) \\
\hline \multirow{2}{*}{ Gender } & Male & 43 & 25.3 \\
\cline { 2 - 4 } & Female & 127 & 74.7 \\
\hline \multirow{4}{*}{ Age } & In their early to mid-20s & 77 & 45.3 \\
\cline { 2 - 4 } & In their late 20s & 21 & 12.4 \\
\cline { 2 - 4 } & In their early to mid-30s & 48 & 28.2 \\
\cline { 2 - 4 } & In their late 30s & 13 & 7.6 \\
\cline { 2 - 4 } & Over 40 & 11 & 6.5 \\
\hline Experience of Online & Some & 131 & 77.1 \\
\cline { 2 - 4 } Community & None & 39 & 22.9 \\
\hline Purchase Experience of & Some & 91 & 53.5 \\
\cline { 2 - 4 } Online Community & None & 79 & 46.5 \\
\hline \multirow{2}{*}{$\begin{array}{c}\text { Internet shopping } \\
\text { Expenditure of a } \\
\text { Monthly Average }\end{array}$} & Under \$100 & 48 & 28.4 \\
\cline { 2 - 4 } & $\$ 100-200$ & 19 & 11.2 \\
\cline { 2 - 4 } & $\$ 200-300$ & 19 & 11.2 \\
\hline
\end{tabular}

Confirmatory factor analysis (CFA) was employed to examine both the goodness-of-fit of the measurement model and the reliability and validity of the scale items [30]. As indicated in Table 3, the fit indices of the measurement model were as follow: $\chi^{2}=$ $241.616(\mathrm{df}=126, \mathrm{p}=.000), \chi^{2} / \mathrm{df}=1.918, \mathrm{GFI}=0.874, \mathrm{IFI}=0.974, \mathrm{TLI}=0.964, \mathrm{CFI}=$ 0.974 , and RMSEA $=0.074$, indicating that the model reasonably fits the data. Multiple measurement items are highly reliable for measuring each construct because all of the Cronbach's alpha values are above 0.9 [31]. Convergent validity is also acceptable because all the item loadings exceed 0.8, composite reliabilities exceed 0.9, and average variance extracted (AVE) for each construct exceed 0.7 [32]. Discriminant validity is acceptable because the square roots of AVE are higher than the inter-construct correlations as shown in Table 4 [32].

Table 3. Confirmatory Factor Analysis

\begin{tabular}{|c|c|c|c|c|c|c|c|}
\hline Factor & Items & Loading & S.E. & t-Value & $\begin{array}{c}\text { Cronbach's } \\
\boldsymbol{\alpha}\end{array}$ & $\begin{array}{l}\text { Composite } \\
\text { Reliability }\end{array}$ & AVE \\
\hline \multirow{3}{*}{ PA } & $\mathrm{Pa} 1$ & 0.890 & - & - & \multirow{3}{*}{0.946} & \multirow{3}{*}{0.948} & \multirow{3}{*}{0.860} \\
\hline & $\mathrm{Pa} 2$ & 0.954 & .048 & 21.365 & & & \\
\hline & $\mathrm{Pa} 3$ & 0.937 & .049 & 20.387 & & & \\
\hline \multirow{4}{*}{ PB } & $\mathrm{Pb} 1$ & 0.806 & - & - & \multirow{4}{*}{0.921} & \multirow{4}{*}{0.926} & \multirow{4}{*}{0.758} \\
\hline & $\mathrm{Pb} 2$ & 0.935 & .071 & 15.126 & & & \\
\hline & $\mathrm{Pb} 3$ & 0.847 & .086 & 11.581 & & & \\
\hline & $\mathrm{Pb} 4$ & 0.889 & .073 & 14.084 & & & \\
\hline \multirow{3}{*}{ PCM } & Pcm1 & 0.854 & - & - & \multirow{3}{*}{0.918} & \multirow{3}{*}{0.937} & \multirow{3}{*}{0.788} \\
\hline & Pcm2 & 0.903 & .059 & 16.477 & & & \\
\hline & Pcm3 & 0.904 & .058 & 16.517 & & & \\
\hline \multirow{3}{*}{ TW } & Tw1 & 0.895 & - & - & \multirow{3}{*}{0.952} & \multirow{3}{*}{0.954} & \multirow{3}{*}{0.873} \\
\hline & Tw2 & 0.966 & .048 & 22.817 & & & \\
\hline & Tw3 & 0.941 & .053 & 21.010 & & & \\
\hline \multirow{3}{*}{ TR } & $\operatorname{Tr} 1$ & 0.923 & - & - & \multirow{3}{*}{0.953} & \multirow{3}{*}{0.958} & \multirow{3}{*}{0.852} \\
\hline & $\operatorname{Tr} 2$ & 0.950 & .040 & 24.312 & & & \\
\hline & $\operatorname{Tr} 3$ & 0.929 & .042 & 22.409 & & & \\
\hline \multirow{2}{*}{ PI } & Pi1 & 0.937 & - & - & \multirow{2}{*}{0.972} & \multirow{2}{*}{0.972} & \multirow{2}{*}{0.920} \\
\hline & Pi2 & 0.975 & .034 & 29.958 & & & \\
\hline
\end{tabular}




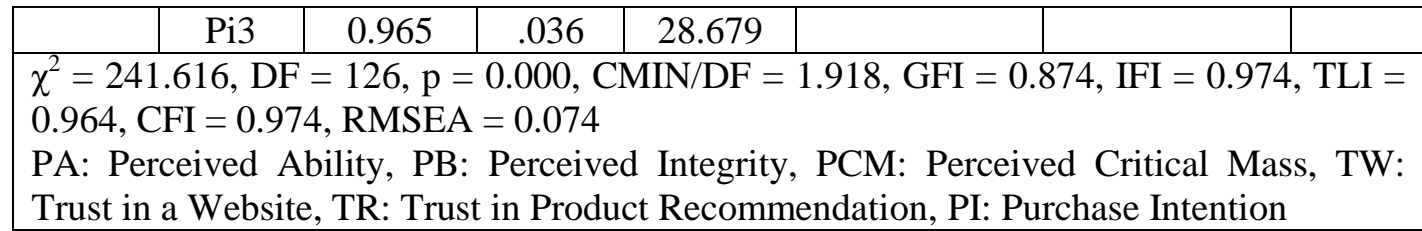

Table 4. Discriminant Validity Analysis

\begin{tabular}{|c|c|c|c|c|c|c|}
\hline & PA & PB & PCM & TW & RT & PI \\
\hline PA & $\mathbf{0 . 9 2 7}$ & & & & & \\
\hline PB & 0.792 & $\mathbf{0 . 8 7 1}$ & & & & \\
\hline PCM & 0.762 & 0.852 & $\mathbf{0 . 8 8 8}$ & & & \\
\hline TW & 0.639 & 0.649 & 0.680 & $\mathbf{0 . 9 3 4}$ & & \\
\hline TR & 0.683 & 0.705 & 0.699 & 0.822 & $\mathbf{0 . 9 2 3}$ & \\
\hline PI & 0.674 & 0.729 & 0.803 & 0.710 & 0.755 & $\mathbf{0 . 9 5 9}$ \\
\hline
\end{tabular}

The squared roots of the AVE values are in bold type on the diagonal.

PA: Perceived Ability, PB: Perceived Integrity, PCM: Perceived Critical Mass, TW: Trust in a Website, TR: Trust in Product Recommendation, PI: Purchase Intention

A second-order confirmatory factor analysis determines the importance of each dimension [33]. The results of a second-order confirmatory factor analysis of social network showed that the fit indices suggest a good fit of the second-order model to the data $\left(\chi^{2}=49.462, \mathrm{df}=29, \mathrm{p}=0.010, \chi^{2} / \mathrm{df}=1.706, \mathrm{GFI}=0.944, \mathrm{IFI}=0.989, \mathrm{TLI}=\right.$ $0.983, \mathrm{CFI}=0.989$, RMSEA $=0.065$ ). Perceived ability has a factor loading of 0.870 , perceived integrity has a factor loading of 0.957 , and perceived critical mass has a factor loading of 0.961 as a second-order factor.

A structural modelling (SEM) was used to test the hypotheses with the software AMOS (Analysis of Moment Structures) 18.0. As shown in Table 5, the fit indices of the path model were identified to reasonably close the data $\left(\chi^{2}=268.889, \mathrm{df}=132, \mathrm{p}=0.000, \chi^{2} / \mathrm{df}\right.$ $=2.037$ GFI $=0.859$, IFI $=0.969$, TLI $=0.960$, CFI $=0.969$, RMSEA $=0.078)$. The findings of the hypotheses testing were as followed. $\mathrm{H} 1, \mathrm{H} 2, \mathrm{H} 3$, and $\mathrm{H} 4$ were significant at $\mathrm{p}<0.001$ and H6 was significant at $\mathrm{p}<0.01$. However, H5 was not significant at $\mathrm{p}<$ 0.05 . Thus, five hypotheses were supported.

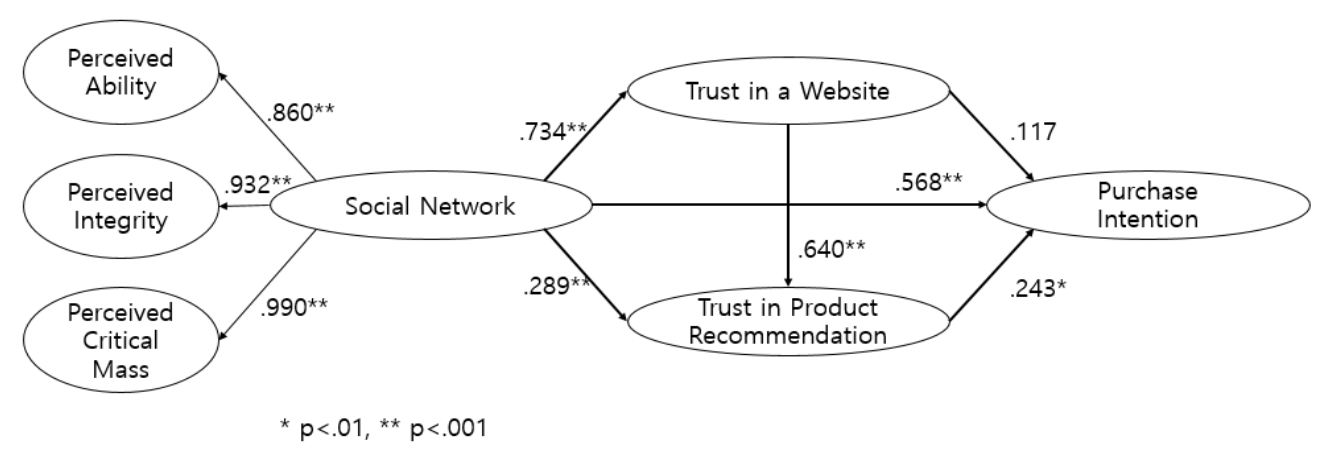

Figure 2. Structural Model

Table 5. Results of Model Testing

\begin{tabular}{|l|c|c|c|c|}
\hline \multicolumn{1}{|c|}{ Hypothesis: Path } & Estimate & S.E. & t-value & Result \\
\hline H1: Social network $\rightarrow$ Trust in a website & 0.734 & 0.068 & 9.553 & Supported \\
\hline $\begin{array}{l}\text { H2: Social network } \rightarrow \text { Trust in product } \\
\text { recommendation }\end{array}$ & 0.289 & 0.069 & 4.364 & Supported \\
\hline H3: Trust in a website $\rightarrow$ Trust in & 0.640 & 0.079 & 9.495 & Supported \\
\hline
\end{tabular}




\begin{tabular}{|l|l|l|l|l|}
\hline product recommendation & & & & \\
\hline $\begin{array}{l}\text { H4: Social network Purchase } \\
\text { intention }\end{array}$ & 0.568 & 0.079 & 7.184 & Supported \\
\hline $\begin{array}{l}\text { H5: Trust in a website } \rightarrow \text { Purchase } \\
\text { intention }\end{array}$ & 0.117 & 0.100 & 1.318 & Rejected \\
\hline $\begin{array}{l}\text { H6: Trust in product recommendation } \rightarrow \\
\text { Purchase intention }\end{array}$ & 0.243 & 0.091 & 2.585 & Supported \\
\hline $\begin{array}{l}\chi^{2}=268.889, \mathrm{DF}=132, \mathrm{p}=0.000, \mathrm{CMIN} / \mathrm{DF}=2.037, \mathrm{GFI}=0.859, \mathrm{IFI}=0.969, \mathrm{TLI}= \\
0.960, \mathrm{CFI}=0.969, \mathrm{RMSEA}=0.078\end{array}$ \\
\hline
\end{tabular}

\section{Conclusions}

This study explored the effects of trust in a website and trust in product recommendation on purchase intention through social network service (perceived ability, perceived integrity, and perceived critical mass). The results show several interesting implications as follows. First, this study showed that the formation of trust in a website and trust in product recommendation is positively affected by social network service (perceived ability, perceived integrity, and perceived critical mass). Interestingly, perceived critical mass has more effect than that of perceived ability and perceived integrity. This is inconsistent with Hsiao et al.' study [10] which suggested that perceived ability has more effect than that of the other factors. This implies that trust in a website and trust in product recommendation of social shopping are associated with risk-taking decision and consumers tend to depend more on large numbers of other shoppers. Thus, perceived critical mass of the product and website evaluations in a social network may be a primary predictor for trust in a website and trust in product recommendation.

Second, the results revealed that consumers' trust in a website strongly affects their trust in product recommendation. Shoppers may trust more the product recommendations on a social shopping website which they depend on. This is consistent with previous studies on trust [34]. The higher trust in a website is, the higher trust in product recommendation is. Meanwhile, social network service has more effect on trust in a website compared to trust in product recommendation. Thus, trust in a website may be more important factor for trust in product recommendation.

Third, this study demonstrated that social network service and consumers' trust in product recommendation positively affect purchase intention but consumers' trust in a website does not affect. In previous studies trust in a website is presented as an important factor of online purchase intention [26, 27]. However, the results of this study showed that the effect of trust in a website on purchase intention is not significant at $p<0.05$. Rather, the effect of trust in product recommendation on purchase intention is significant at $p<$ 0.01. This is partly consistent with Hsiao et al.'s study [10]. Interestingly, social network service has more effect on purchase intention than that of trust in product recommendation. This implies that consumers depend more on social network service than trust in product recommendation when purchasing products on the social shopping website.

Fourth, a few studies have investigated the relationship between trust in product recommendation and purchase intention in social shopping. This study contributes to more understanding of the effect of trust in product recommendation in social shopping. Thus, this paper identifies these two types of trust and emphasizes the importance of them in the social shopping environment.

As the findings presented in this study indicate, in order to increase performance, social shopping managers should focus on building strong trust in a website and trust in product recommendation through social network service (perceived ability, perceived integrity, and perceived critical mass). 
The results of this study should be interpreted with caution because there are some limitations. First, deriving more generalized results would likely require applying the same model in other provinces of South Korea. Second, consumers' attitudes toward these two types of trust in social shopping can vary over time. Such bias in the sample might influence the results. It would be meaningful to conduct the same study in another time point and compare the results.

\section{References}

[1] C. Wang and P. Zhang, "The Evolution of Social Commerce: An Examination from the People, Business, Technology, and Information Perspective", Communications of the AIS, vol. 31, no. 5, (2012), pp. 105-127.

[2] R. Olbrich and C. Holsing, "Modeling Consumer Purchasing Behavior in Social Shopping Communities with Clickstream Data", International Journal of Electronic Commerce, vol. 16, no. 2, (2011), pp. 15-40.

[3] J. Shen, "Social Comparison, Social Presence, and Enjoyment in the Acceptance of Social Shop-ping Websites", Journal Electronic Commerce Research, vol. 13, no. 3, (2012), pp. 198-212.

[4] I. Lee and K. Lee, "Social Shopping Promotions from a Social Merchant's Perspective", Business Horizons, vol. 55, no. 5, (2012), pp. 441-451.

[5] K. Yang, X. Li, H. J. Kim and Y. H. Kim, "Social Shopping Website Quality Attributes Increasing Consumer Participation, Positive eWOM, and Co-Shopping: The Reciprocating Role of Participation", Journal of Retailing and Consumer Services, vol. 24, (2015), pp. 1-9.

[6] N. Hajli, "Handbook of Research on Integrating Social Media into Strategic Marketing", Hershey PA, New York, (2015).

[7] M. Shanmugama, S. Sunb, A. Amidic, F. Khanid and F. Khani, "The Applications of Social Commerce Constructs”, International Journal of Information Management, vol. 36, no. 3, (2016), pp. 425-432.

[8] M. Featherman and N. Hajli, "Self-Service Technologies and E-Services Risks in Social Commerce Era", Journal of Business Ethics, (2015), pp. 1-19.

[9] W. H. Chih, L. C. Huang, T. J. Yang and H. P. Cho, "Online Relational Bond, Trust and Customer Loyalty", International Conference on Information Management and Engineering, Kuala Lumpur, IEEE Computer Society, Los Alamitos, CA, pp. 138-141, (2009).

[10] K. L. Hsiao, J. C. C. Lin, X. Y. Wang, H. P. Lu and H. Yu, "Antecedents and Consequences of Trust in Online Product Recommendations: An Empirical Study in Social Shopping", Online Information Review, vol. 34, no. 6, (2010), pp. 935-953.

[11] H. Lou, W. Luo and D. Strong: "Perceived Critical Mass Effect on Groupware Acceptance", European Journal of Information Systems, vol. 9, no. 2, (2000), pp. 91-103.

[12] M. C. Ridings, D. Gefen and B. Arinze, "Some Antecedents and Effects of Trust in Virtual Communities", Journal of Strategic Information Systems, vol. 11, no. 3/4, (2002), pp. 271-295.

[13] H. Sung, W. Kim and J. Shin, "The Effect of Social Network on Purchase Intention through Two Types of Trust", Asia-pacific Proceedings of Applied Science and Engineering for Better Human Life, vol.3, pp. 44-47, (2016).

[14] H. H. Chang and S. W. Chen, "The Impact of Online Store Environment Cues on Purchase Intention", Online Information Review, vol. 32, no. 6, (2008), pp. 818-841.

[15] D. H. McKnight, V. Choudhury and C. Kacmar, "The Impact of Initial Consumer Trust on Intentions to Transact with a Website: A Trust Building Model", Journal of Strategic Information Systems, vol. 11, no. 3, (2002), pp. 297-323.

[16] J.-J. Wu and Y.-S. Chang, "Effect of Transaction Trust on E-Commerce Relationships between Travel Agencies", Tourism Management, vol. 27, no. 6, (2006), pp. 1253-1261.

[17] J. Chen, H. Xu and A. B. Whinston, "Moderated Online Communities and Quality of User Generated Content", Journal of Management Information Systems, vol. 28, no. 2, (2011), pp. 237-268.

[18] R. C. Mayer, J. H. Davis and F. D. Schoorman, "An Integrative Model of Organizational Trust", Academy of Management Review, vol. 20, no. 3, (1995), pp. 709-734.

[19] B. Lu, W. Fan and M. Zhou, "Social Presence, Trust, and Social Commerce Purchase Intention: An Empirical Research", Computers in Human Behavior, vol. 56, (2016), pp. 225-237.

[20] P. Mardsen, "Social Commerce, Monetizing Social Media", Hamburg, Germany: Syzygy Deutschland Gmbh, (2010).

[21] eMarketer, "The Growing Influence of Online Social Shoppers", available at: www.emarketer.com/Article.aspx?id=1006146 (accessed 1 July 2009).

[22] P. Keen, G. Ballance, S. Chan and S. Schrump, "Electronic Commerce Relationships: Trust by Design", Prentice Hall, (1999)

[23] Y. D. Wang and H. H. Emurian, "An Overview of Online Trust: Concepts, Elements, and Implications", Computers in Human Behavior, vol. 21, no. 1, (2005), pp. 105-125.

[24] T. S. H. Teo and Y. Yu, "Online Buying Behavior: A Transaction Cost Economics Perspective", Omega, vol. 33, no. 5, (2005), pp. 451-465. 
[25] J. A. Chevalier and D. Mayzlin, "The Effect of Word of Mouth on Sales: Online Book Reviews", Journal of Marketing Research, vol. 43, no. 3, (2006), pp. 345-354.

[26] D. J. Kim, D. L. Ferrin and H. R. Rao, "A Trust-Based Consumer Decision-Making Model in Electronic Commerce: The Role of Trust, Perceived Risk, and Their Antecedents", Decision Support Systems, vol. 44, no. 2, (2008), pp. 544-564.

[27] F. Rahimnia and J. F. Hassanzadeh, "The Impact of Website Content Dimension and E-Trust on EMarketing Effectiveness: The Case of Iranian commercial Saffron Corporations", Information \& Management, vol. 50, no. 5, (2013), pp. 240-247.

[28] Y. Bai1, Z. Yao and Y. F. Dou, "Effect of Social Commerce Factors on User Purchase Behavior: An Empirical Investigation from renren.com”, International Journal of Information Management, vol. 35, no. 5, (2015), pp. 538-550.

[29] D. Gefen: "E-Commerce, the Role of Familiarity and Trust", Omega, vol. 28, no. 6, (2000), pp. 725-737.

[30] J. C. Anderson and D. W. Gerbing, "Assumptions and Comparative Strengths of the Two-Step Approach", Sociological Methods \& Research, vol. 20, no. 3, (1992), pp, 321-333.

[31] J. F. Hair, R. Anderson, R. Tatham and W. Black, "Multivariate Data Analysis (5th ed.)", Prentice-Hall, New York, (1998).

[32] C. Fornell and D. Larcker, "Evaluating Structural Equation Models with Unobservable Variables and Measurement Error", Journal of Marketing Research, vol. 18, no. 1, (1981), pp. 39-50.

[33] J. I. Shin, K. H. Chung, J. S. Oh and C. W. Lee, "The Effect of Site Quality on Repurchase Intention in Internet Shopping through Mediating Variables: The Case of University Students in South Korea", International Journal of Information Management, vol. 33, iss. 3, (2013), pp. 453-463.

[34] N. Panteli and S. Sockalingam, "Trust and Conflict within Virtual Interorganizational Alliances: A Framework for Facilitating Knowledge Sharing”, Decision Support Systems, vol. 39, no. 4, (2005), pp. 599-617.
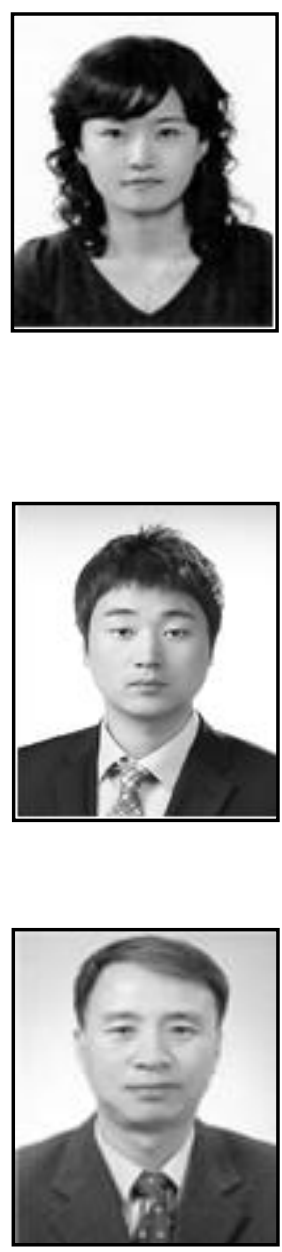

\section{Authors}

Haengnam Sung, she received a B.S. degree in Management Information System from Gyeongsang National University, Korea, 2000, M.S. degree in Management Information System from Gyeongsang National University, Korea, 2003, and Ph. D. degree in Management Information System from Gyeongsang National University, Korea, 2009. In 2004, she joined the lecturer of Gyeongsang National University(GNU) and Gyeongnam National University of Science and Technolgy(GnTech). Her research interests include MIS, Electronic Commerce and Learning(e-Learning, m-Learning).

Wonjong Kim, he is the co-author of the paper. He is a candidate for $\mathrm{Ph}$. D. in the Department of Business Administration at Gyeongsang National University, Jinju, South Korea. He had finished Standard MBA course in Ateneo Graduate School of Business in The Philippines. His current research interests include CSR activities, e-commerce, internet marketing and market orientation. He has published papers in journals such as The Journal of Internet Electronic Commerce Research.

Jae-Ik Shin, he is an Assistant Professor of Department of E-Business at Gyeongnam National University of Science and Technology, South Korea. He received his Ph.D. in Management from Gyeongsang National University, South Korea. His current research interests include internet marketing, tourism marketing, corporate social responsibility, and service marketing. He has published papers in journals such as International Journal of Information Management, INFORMATION (Japan), ICIC Express Letters, Part B: 
Applications, Asia Pacific Journal of Marketing and Logistics, International Journal of $\mathrm{u}$ - and e- Service, Science and Technology, Korean Journal of Tourism Research, The Journal of Internet Electronic Commerce Research, The Academy of Customer Satisfaction Management, International Journal of Business and Information, and Journal of the Korea Entrepreneurship. 